\title{
Drug information
}

\section{Where to look for drug information on the Internet}

\author{
by Mignon Adams
}

I nformation distributed about prescription drugs is tightly controlled by federal regulation both in this country and in others. Thus, the information found about prescription drugs on the Web, unlike many other topics searched, is likely to be accurate. The challenge is to find complete information and descriptions written at an appropriate level, be it health professional or consumer.

A description of a drug, including its indications for therapeutic use, dosage, contraindications, etc., is called a drug monograph.

\section{Product Package Inserts}

The pamphlet often included with a prescription drug, the Product Package Insert (PPI), consists of the wording required and approved by the Federal Drug Administration. The content of this pamphlet is essentially identical to the monograph inclided in the Physicians Desk Reference and is written by employees of the pharmaceutical manufacturer. Most often, the information from the PPI is also listed on the manufacturer's site; here it is generally called "prescribing information."

- Scholz Healthcare. Scholz Healthcare is a German company that sells software prod- ucts and services to the U.S. pharmaceutical industry. The company maintains a site where visitors can search for either the generic or brand name of a drug and be linked directly to the prescribing information on the Web site of the drug manufacturer. This is the same information listed in the Pbysicians Desk Reference (and it may be more up-to-date). Access: http://www.ditonline.com/monograph/ index.html.

- Druginfonet. Those who maintain Druginfonet have scanned in both the official package insert and the patient package insert. Again, it is the same information that is in the Pbysicians Desk Reference, although the number of drugs listed may not be as large. Access: http://www.druginfonet.com/drug.htm.

- Federal Drug Administration (FDA). The FDA site not only contains a great deal of useful information, but it is also well designed and easy to navigate. It lists drug labeling information (from which the PPI is obtained) for drugs approved since 1998, as well as consumer-friendly versions; new drug approvals; and discussions of items currently in the news. Also available online is the $O r$ ange Book, which lists "therapeutic equivalents" (generic drugs that can replace a brandname drug). The homepage directs users to

\section{About the author}

Mignon Adams is director of Library and Information Services at the University of the Sciences in Philadelphia, e-mail: m.adams@usip.edu 
information for consumers, patients, health professionals, industry, press, women, seniors, and kids. Anyone who wants to know about the pharmaceutical regulatory system in the United States should begin here. $A c$ cess: hetp://www.fda.gov.

\section{Food and Drug Administration}

\section{Other information about prescription drugs}

Most pharmacists consider the package insert useful but limited because it contains no more information than is required by law and it is written in standard regulatory style. Other sites provide information that is not written by the manufacturer, and therefore their monographs are considered to be less biased and are often much more clearly written.

- Rxlist. Rxlist was created by Neil Sandow, a hospital pharmacist. This well-respected site contains the same drug monographs that appear in Mosby's GenRx. In addition to therapcutic information, other useful information is given, such as the annual cost of taking the drug and brand names under which the drug may be sold in other countries. Excellent monographs for patients, in both English and Spanish, are found here. You can also identify a pill here by entering its imprint code. There are a small, but very good, number of monographs on herbals. Finally, there is a collection of Rx cartoonsbut only your pharmacist may find them funny. Access: http://rxlist.com.

- Drug Facts and Comparison. This highly respected publication, known generally only to pharmacists, examines drugs within a particular class-say, antidepressants or calcium channel blockers-and compares their therapeutic action, dosage, precautions, and drug interactions. By registering on their Web site, you may access an abridged version of the publication at no cost; access to the complete version is by paid subscription only. There is a consumer section with good monographs. There is also a drug interaction index, as well as drug quizzes for the health professional. Access: http://www.drugfacts. com.

- The U.S.P. Drug Information for the Patient. This has long been a source of choice for reliable and understandable information for patients. It is available many places on the Web, some of which ask the reader to register. The simplest site to find it (and with no registration) is the drug information section of the National Library of Medicine's MedlinePlus. Not only are prescription drugs listed, but also commonly used over-thecounter drugs. Access: http://www.nlm.nih. gov/medlineplus/.

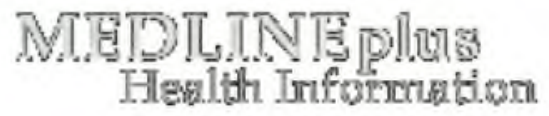

- The People's Pharmacy. This book, written by Joe (pharmacologist) and Terry (nurse) Graedon, has gone through many editions. The Graedons now have their own Web site, which includes their clear writeups of the top 150 prescription drugs (which account for the majority of prescriptions). Also included are informed looks at home remedies, such as bag balm for dry skin. Access: http://www.healthcentral.com/ peoplespharmacy/peoplespharmacy.cfm.

\section{Also for consumers}

- FDA Consumer. This magazine, published by the FDA for consumers, is online. Articles may be on a recent new drug, issues in regulation or the pharmaceutical industry, food, or any of the areas the FDA covers. Back issues date to 1995, and they're all searchable by keyword. Access: http://www $\mathrm{fda} . \mathrm{gov} / \mathrm{fdac} /$.

\section{FDAConsumer}

- Physician's Desk Reference (PDR). $P D R$ has its own Web site. $P D R$ isn't free, even though the monographs contained within it are generally free by going to vari-

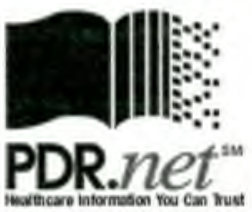
ous manufacturers sites. But $P D R$ for Families and $P D K$ Family Healtb Encyclopedia are. Access http://www.pdr.net/. 
- University of Maryland School of Pharmacy. The University of Maryland School of Pharmacy has had an "ask the pharmacist" site for many years. It is now done in partnership with Giant Foods of Maryland. A sample question was answered fully in about five hours by a Maryland pharmacy school faculty member. Access: http://www. giantfood.com/pharm_ask_pharmacist.cfm.

- Rite-Aid. This chain pharmacy's site has an "Ask a Pharmacist" feature. A sample question here was answered briefly in just over an hour. Access: http:// www.riteaid.com.

- PubMed. To locate studies done with various drugs and drug therapies, the best place is Medline, available free to anyone at PubMed. Searches can be done either by brand name or by generic name. Access: http://www.ncbi.nlm.nih.gov/PubMed/.

\section{PublMed}

\section{National \\ Library of Medicine NIM}

\section{Online pharmacies ${ }^{1}$}

- National Association of Boards of Pharmacy. In response to concerns about unethical or substandard online pharmacies, the National Association of Boards of Pharmacy has developed criteria to verify that online stores meet standards. At the present time 17 online pharmacies have been verified. Access: http://www.nabp.net/vipps/ intro.asp.

\section{Clinical trials}

Both consumers and health professionals may want to know what drugs are currently being tested for which conditions.

- ClinicalTrials. The National Institute of Health has developed ClinicalTrials to provide patients, family members, and members of the public with current information about clinical research studies. The site also provides general information about clinical trials. Access: http://clinicaltrials.gov.

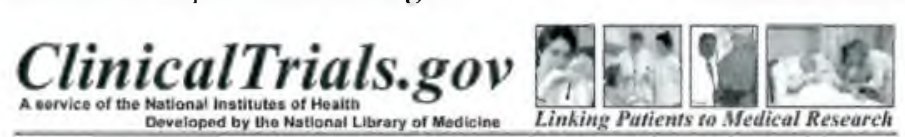

\section{Natural products}

Herbals, minerals, and vitamins are classed as dietary supplements. With the passage of the Dietary Supplements Act of 1994, the FDA is no longer responsible for assuring the safety of the ingredients in dietary supplements before they are marketed. Drugs must be proved to be effective and safe; dietary supplements have no such requirement. Web sites that promote natural products are generally inaccurate, filled with anecdotal claims and personal testimony. Fortunately, there are some Web sites that can provide information about herbals that is based on evidence rather than conjecture.

- Longwood Herbal Task Force. This joint effort of Boston's Children's Hospital, Massachusetts College of Pharmacy and Health Science, and the Dana Farber Cancer Institute, maintains one of the best herbal Web sites. Included here are lengthy monographs that link claims with the scientific evidence as well as leaflets for both clinicians and patients. Its only drawback is that the number of herbals covered is limited. Access: http:// www.mcp.edu/herbal/.

- HerbMed. The Alternative Medicine Foundation, a nonprofit organization located in Bethesda, has created this useful database, which contains summaries of published studies done with commonly used botanicals, with links to the articles' abstracts in PubMed. Adverse effects are linked to the FDA's adverse events reports. Access: http://www. herbmed.org/.

- National Center for Complementary and Alternative Medicine. This is the part of the National Institute of Health that sponsors research on complementary and alternative medicine. At their site, you'll find fact sheets on natural products and also "consensus reports," summaries of conferences that came to conclusions about the use of certain alternative medicines. Access: http:// nccam.nih.gov/.

- International Bibliographic Information on Dietary Supplements (IBIDS). This bibliographic database of "published, international

- Centerwatch. This site considers itself the information source for the clinical trials industry. Access: http://www.centerwatch. com. scientific literature on dietary supplements, including vitamins, minerals, and botanicals." You may choose to search the full database or for consumer references or peer-reviewed 
journals only. Access: http://ods.od.nih.gov/ databases/ibids.html.

- Consumerlabs. One of the difficulties with herbals is that often the product that you buy may contain very little of the active ingredient. Consumerlabs tests natural products to see what they actually contain; some of their results are available for nonsubscribers. Access: http://consumerlabs.com.

- A Mini-Course in MEDICAL BO'TANY. For those who want to learn about natural products themselves, there is "A Mini-Course in MEDICAL BOTANY" by James A. Duke, one of the gurus on the use of herbals. The site contains his actual lecture notes. Access. http://www.ars-grin.gov/duke/syllabus/

\section{Illegal drugs}

Illegal use of drugs may involve either the use of illegal substances, such as cocaine or heroin, or the illegal use of prescription drugs, such as barbiturates and tranquilizers. Understanding how these drugs act upon the body may help in understanding the addiction.

- National Institute on Drug Abuse. This is a nicely designed site with clearly marked sections for health professionals, parents and teachers, and students. Research reports, statistics, directories of street names for drugs, and a host of other information can be found here. Access: http://www.nida. nih.gov/.

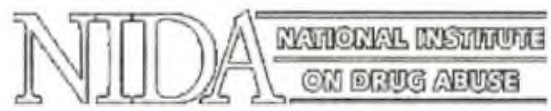

- Drug Enforcement Administration. This Web site contains a listing of "drugs of concern," as well as access to schedules of controlled substances and statistics, such as the number of meth lab seizures over the last decade. Access: http://www.usdoj.gov/ dea/.

- Center for Substance Abuse Research

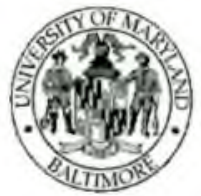
(CESAR). Located at the University of Maryland, the CESAR site provides good basic information and numerous charts and statistics. Access: http:// www.cesar.umd.edu/.

\section{Drug sales statistics}

- Hoover's Online. The pharmaceutical industry is one of the largest in the United States. Information about the industry itself can be found on business sites, such as Hoover's Online. Access: http:// www.hoovers.com.

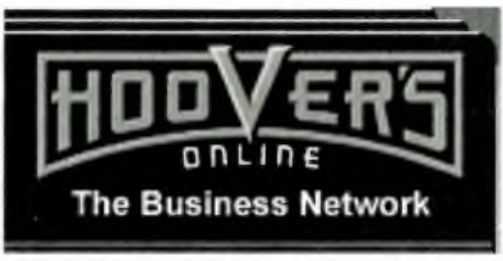

- Drug Topics. Very often students seek statistics on the use or sales of prescription drugs. Once a year, a marketing firm, IMS America, does a National Prescription Audit, sampling the number of prescriptions per drug. Some of its results can be found on the Drug Topics site, a pharmacy trade magazine. Its "Pharmacy Facts and Figures" lists the top 200 brand-name and generic drugs, both by number of prescriptions and by retail sales. Access: http://dt.pdr.net/dt/.

\section{DRUSTOPHaseom THE ONLINE NEWSMA GAZINE FOA PHARMACISTS}

\section{Note}

1. PharmInfonet (pharminfo.com) has been a primary gateway for pharmacy information for a number of years. Unfortunately, it has evidently gone out of existence.

\section{("Information literacy. . ." cont. from page 690)}

major theme that ran through my interviews and other work observations is that it is critical that employees be good learners in any fast-paced work environment.

3. The newly developed TekXam, "the nationwide standard for technical literacy," incorporates many information literacy skills. Note the test objectives and online quiz at their Web site (http://www tekxam. com).

4. "Information Literacy in the Information Age: Sabbatical Project Report," including the instructional modules, is available on the Web at http://www.cabrillo.cc.ca.us/ itsmalley or http://www.topsy.org. 


\section{Find it. Faster.}

You just got a request for a list of grocery stores in a three-state area with more than 20 employees.

You could search through dozens of reference sources to create that list. Or, you could call the Library Division of infoUSA.

We offer the country's most extensive databases of business and residential information. And, you choose the format you want: print, CD-ROM or via the Internet.

Want more information? Call us today at 1-800-808-1113 or e-mail: library@infoUSA.com.

Your search is over.

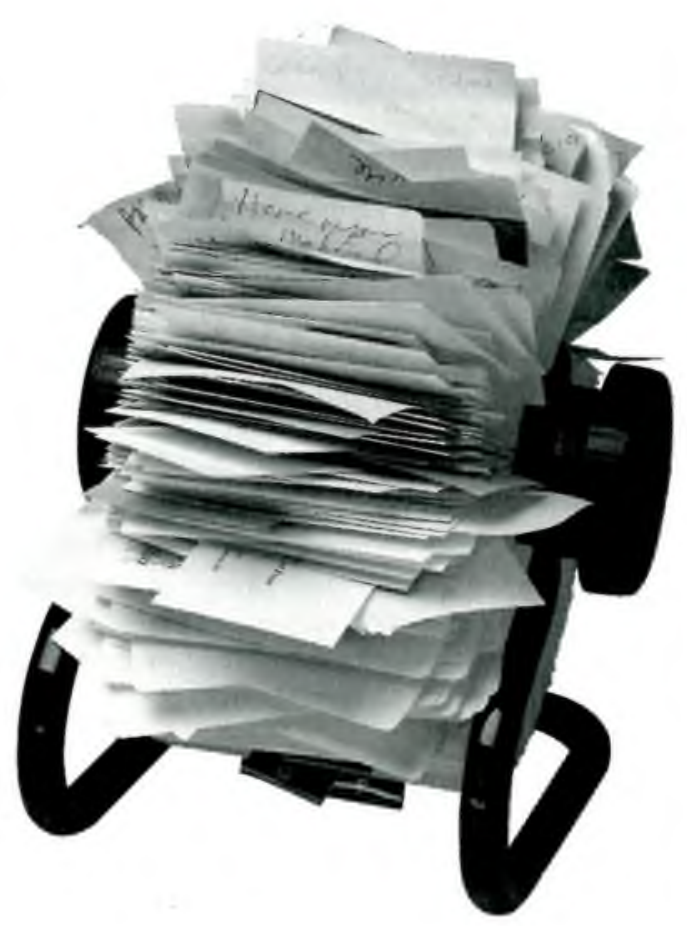

\section{infoUSA \\ Library Division}

5711 S. 86th Circle • P.O. Box 27347 - Omaha, NE 68127

Phone: (402) 593-4523 - Fax: (402) 596-7688 - www.libraryUSA.com

23580 